\title{
Estrategias publicitaria y promocional de las series televisivas: Breaking Bad en los medios de comunicación
}

Gloria Jiménez Marín | gloria_jimenez@us.es

UNIVERSIDAD DE SEVILLA

Rodrigo Elías Zambrano | rodrigoelias@us.es

UNIVERSIDAD DE SEVILLA

Resumen: Cual producto susceptible de ser vendido, comprado o consumido, las series televisivas emplean diversas estrategias y tácticas publicitarias para conseguir cuotas de audiencia, espectadores. Desde la promoción en medios convencionales a acciones below the line, la serie de la norteamericana AMC Breaking Bad, ha empleado numerosas tácticas comunicativas para convertirse en una de las series más vistas en la historia reciente de la televisión.

Palabras clave: Estrategia, Medios, Publicidad, Serie televisiva.

Abstract: Such a product capable of being sold, purchased or consumed, the television series employ various advertising strategies and tactics to get audience share. From conventional media promotion to below the line actions, the American AMC series 'Breaking Bad' has employed numerous communication tactics to become one of the most popular series in recent television history.

Key words: Advertising, Media, Television serie, Strategy. 


\section{Introducción}

La televisión ofrece al espectador una nueva realidad audiovisual que alcanza unos límites insospechados hasta hace bien poco tiempo. Nos referimos a la calidad de guión y técnica, actores, directores de las series televisivas... Pero a todo ello debemos añadir, además, las estrategias promocionales y acciones publicitarias que acompañan a las series durante su etapa de vida en activo ( $y$, en muchos casos, incluso años después).

Hasta hace una década, televisión y cine eran dos productos distintos que jugaban en ligas distintas, tanto a nivel de crítica y premios, como a nivel de espectadores: la unión de un aumento de calidad junto con su promoción hace de las series, en los casos acertados, un producto de éxito (Jiménez y Elías, 2013).

Y es que, si hay un producto audiovisual rentable, ese es la serie televisiva. Aún más si está bien concebida en todas sus características: ejemplos como Cómo conocí a vuestra madre (How I met your mother, CBS, 2005 -), The Big Bang Theory (CBS, 2008 -), Juego de Tronos (Game of Thrones, HBO, 2011-) o Modern Family (ABC, 2009 -) son una gran muestra de rentabilidad en materia audiovisual: Buen guión, buena dirección, buenos actores, buena promoción. Y, el ejemplo que ahora nos ocupa, Breaking Bad (AMC, 2008-), es una muestra más de este fenómeno serial.

La propia calidad de las series ha traído consigo una subida en los niveles de audiencias. Pero, por suerte o por desgracia, la calidad de un producto audiovisual no siempre es sinónimo de audiencia; ni, en el extremo del marketing, una buena campaña publicitaria garantiza tampoco esa audiencia o incluso fidelidad. Los mejores resultados se obtendrán, como en tantos otros productos, en la combinación de un buen producto bien comunicado.

\section{La publicidad de una serie}

Las campañas publicitarias suponen un soporte fundamental para el éxito de una serie, sea publicidad above the line a través de medios tradicionales, sea publicidad below the line a través de nuevos medios.

Aquí hemos de destacar que, si bien la publicidad ha sido un motor fundamental, también es cierto que ésta ha sufrido muchos cambios para poder conseguir impactar en el consumidor de una manera eficaz ( $y$, en la medida de lo posible, de manera eficiente). Estas transformaciones se derivan, entre otros, de las propias variaciones que ha sufrido la industria audiovisual a nivel mundial, cambios que afectan a distintos niveles: tanto en lo que se refiere a tecnología (cambios tecnológicos que han supuesto desde la creación de nuevos medios a la digitalización de contenidos, modificando los existentes) como a nivel psicosociológico y social (cambios que han traído consigo un rol más activo por parte de los espectadores convirtiéndolos, en muchos casos, en prosumidores). 
$Y$ es que el sector audiovisual, en su vertiente televisiva, se encuentra en pleno proceso de evolución, experimentando una gran interactividad con el resto de aparatos de nuestro hogar. Como afirman Ramos, Lozano y Hernández-Santaolalla (2012: 1214):

\begin{abstract}
La transformación provocada por la comunicación interactiva no se ha iniciado con la web 2.0, las redes sociales ni siquiera con internet. Desde nuestro punto de vista, se trata, más bien, de un proceso de cambio lento y progresivo que algunos sectores han estado ignorando durante todo este tiempo.
\end{abstract}

En este sentido, cabe destacar los denominados $\mathrm{HTPC}^{1}$, que suponen una verdadera revolución a la hora de integrar todo el ocio audiovisual (on y off line) en un mismo equipo, así como el desarrollo de las Smart $T V^{2}$, que permiten que un espectador sea capaz de visionar un capítulo de estreno o de la década de los ochenta, acceder a la crítica y extras de un producto audiovisual o comentar en redes sociales su opinión sobre la serie.

Si partimos del enfoque del marketing para un producto, servicio o bien determinado, debemos acudir a la teoría clásica de las 4 P (Producto, Precio, Distribución y Comunicación) a las que Jiménez y Elías (2013) añaden una quinta: las Personas.

A principios de esta década, Lozano y Hermida (2010: 4) manifestaban que "el proceso de construcción del mensaje comercial y las herramientas publicitarias utilizadas para anunciar, por ejemplo, un nuevo detergente no son las mismas que utiliza una empresa de transporte público a la hora de dar a conocer sus nuevos servicios". Y esta es la misma cuestión que ocurre para un producto audiovisual. Aunque, siguiendo a Kotler (2010), las variables de marketing mix que componen la estrategia base son las mismas, los elementos y peculiaridades de una serie son muy distintos. Así, podemos afirmar que para la promoción de una serie debemos tener en cuenta:

Producto: La serie en sí con todos los elementos que la componen: guión, b.s.o., actores.

Precio: En abierto, bajo suscripción o a través de otras fórmulas de pago (alquiler, compra) o libres de pago (préstamo bibliotecario, descarga, visualización en streaming).

Distribución: A través de canales de televisión, internet, venta de temporadas.

Comunicación: Campañas publicitarias, promociones, autopromociones...

Personas: Audiencia, prescriptores, fans.

\footnotetext{
${ }^{1}$ Home Theater Personal Computer es un dispositivo que ejerce de centro multimedia como núcleo de ocio audiovisual integrando: reproductor de Blu-ray, placa base, disco duro, conexión a internet, navegador, conexiones HDMI y USB.

${ }^{2}$ Las Smart TV son modelos de televisores con conexión a internet y posibilidad de instalar y usar aplicaciones diseñadas específicamente para ser utilizadas en televisión.
} 


\section{EE.UU.: AMC y su estrategia de promoción}

AMC es un canal de televisión por cable de nacionalidad estadounidense que centra su principal atención en la emisión de películas y programas de producción propia como series de alta calidad técnica y de guión, entre las que encontramos, por ejemplo, los estrenos de The Walking Dead (AMC, 2010 - ) o Mad Men (AMC, 2007 - ). A esto, además, le suman importantes campañas publicitarias.

En contraposición a otras series que fueron éxito desde el primer episodio, en el caso de Breaking Bad nos encontramos con que, aunque en general recibió críticas muy positivas, no fue hasta el tercer episodio de su primera temporada cuando empezaron a destacar sus datos de audiencia, sumando en cada temporada más telespectadores a través del canal AMC. Así, podemos afirmar que Breaking Bad es la respuesta de AMC, junto con Mad Men ( $A M C, 2007$ - ), al monopolio de series de culto que ostenta HBO desde hace algunos años.

\subsection{Breaking Bad. Identidad visual y naming cuidados al detalle.}

La marca Breaking Bad está elaborada por AMC con gran meticulosidad y multitud de elementos, cuanto menos, curiosos. Partiendo de la trama principal de la serie y su relación con la química, el propio nombre de la serie, en su versión abreviada surge de los símbolos químicos de dos elementos: el bromo o bromino $(\mathrm{Br})$ y el bario $(\mathrm{Ba})$.

El bromo $(\mathrm{Br})$ es un elemento químico líquido, de número atómico 35, de color rojo, volátil y denso. En estado líquido es peligroso para el tejido humano y sus vapores irritan los ojos y la garganta. El significado etimológico del término es "hedor", "pestilencia" igual que el submundo en el que se introduce el protagonista de la serie.

De otra parte, el bario $(\mathrm{Ba})$ es un elemento químico altamente reactivo, de número atómico 56, que reacciona con el cobre y se oxida rápidamente al entrar en contacto con el agua. Es un componente tan reactivo que no existe en estado libre en la naturaleza. Como peculiaridad, podemos decir que algunos de sus compuestos se consideran diamantes... vulgarmente denominados cristal. Curiosamente, 'cristal' (metanfetamina) es el nombre de una droga de diseño.

El diseño de logo de la serie queda reducido, justamente, a los símbolos de esos dos elementos químicos: las siglas del título de la serie.

Imagen 1 


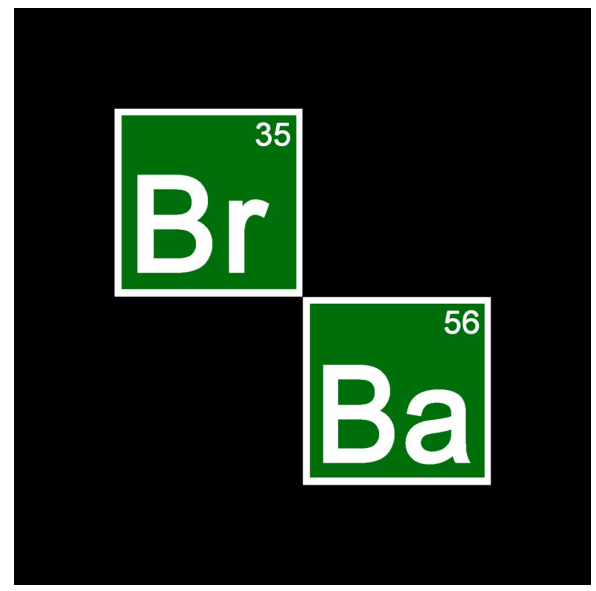

3.2. Seguidores de la serie: la tabla periódica de las muertes de Breaking Bad como parte de la identidad visual.

Tal es el número de seguidores de la serie en EE.UU., que el fenómeno fan se ha convertido en uno de esos prosumidores que comentábamos anteriormente. Y es que uno de los admiradores realizó un juego visual que la propia $A M C$ acabó utilizando en su publicidad: La tabla periódica de las muertes ${ }^{3}$.

En este gráfico aparecen recogidas cada una de las muertes de la serie así como la forma y el momento en que ocurrieron; es decir, gracias a la tabla se puede hacer un repaso a las distintas muertes, quedando registrada la fórmula (química o no) que llevó a los personajes a ese trágico destino: Desde un disparo o un accidente de avión, cada muerte queda recogida con el elemento que las ha provocado.

Esta imagen, llegó a convertirse en una de las imágenes de cabecera de la página oficial de la serie en Facebook.

\footnotetext{
${ }^{3} \mathrm{http}: / /$ www.vayatele.com/ficcion-internacional/la-tabla-periodica-de-las-muertes-de-breaking-bad-laimagen-de-la-semana (consultado el 13/02/2013).
} 


\section{Imagen 2}

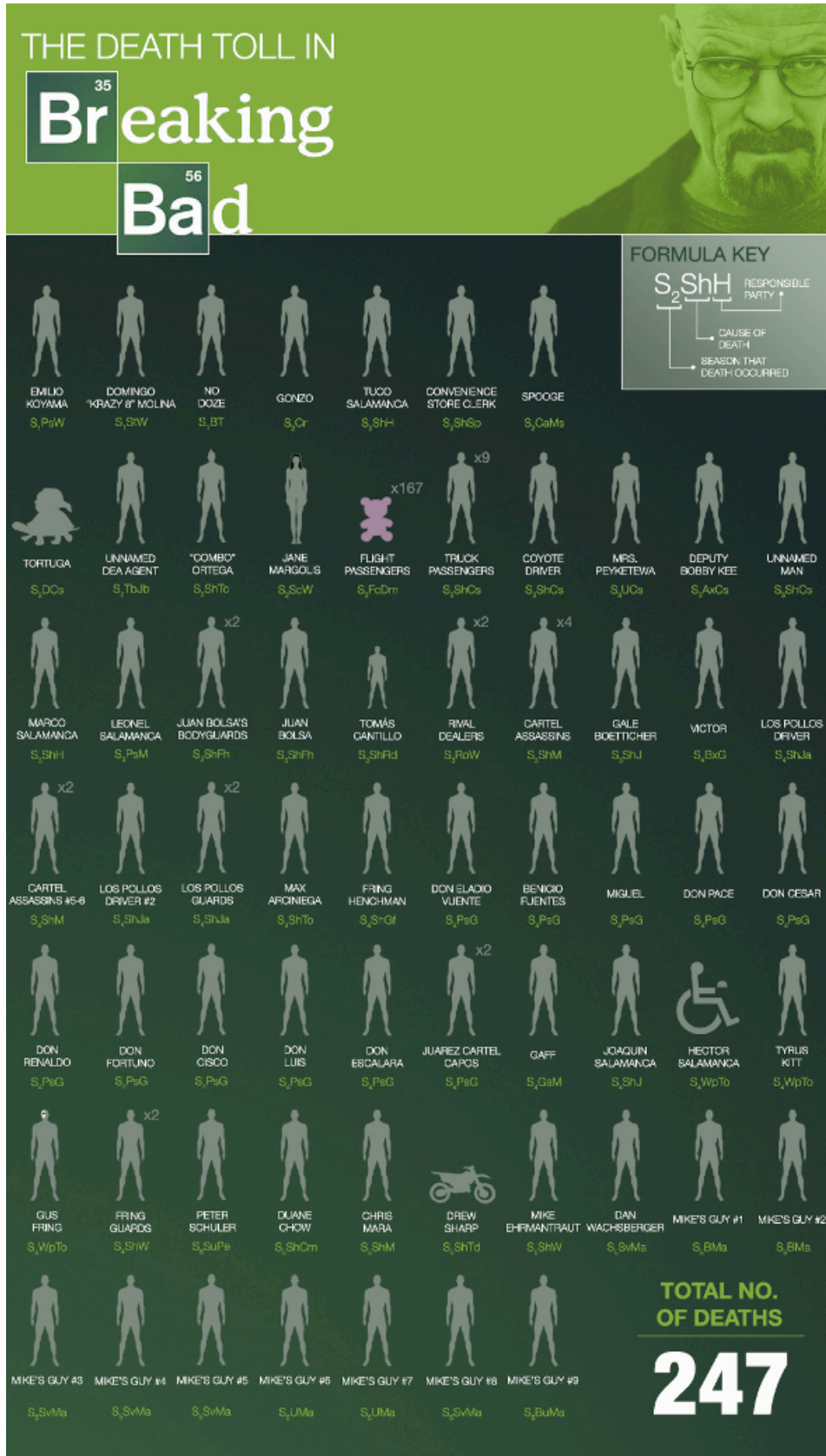

PERIODIC TABLE OF DEATH

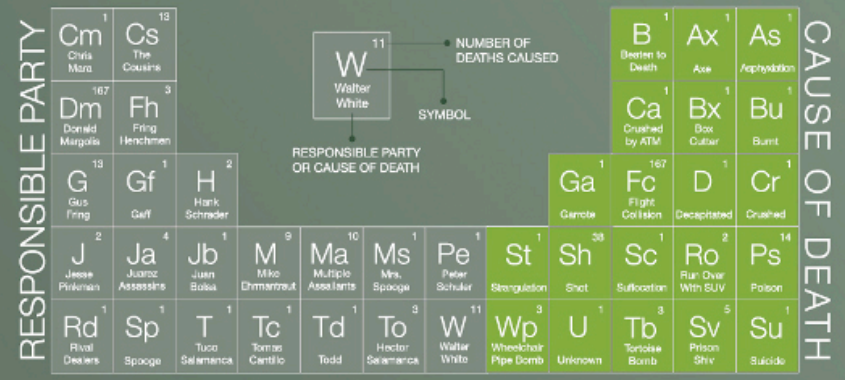

tdylf.com 


\subsection{La publicidad de AMC: Exterior, virales y otras formas de comunicación.}

El canal $A M C$ se caracteriza, entre otras cuestiones, por hacer una promoción de sus productos muy estudiada. Así, la campaña publicitaria de la serie en EE.UU. se compuso de distintas piezas concebidas por y para ser emitidas y expuestas en diversos medios. $Y$ especialmente destacables han sido tanto las campañas de publicidad exterior, como las realizadas para internet.

En el caso de publicidad exterior, es digna de mención la campaña que unía a la serie, con la imagen de Obama y con la marca Weatherproof (marca de ropa de abrigo y montaña estadounidense). El hecho en cuestión fue consecuencia de una campaña que hizo esta marca al colocar una lona publicitaria en Times Square en la que aparecía Obama (con la muralla china de fondo) llevando una de sus cazadoras. Esta campaña trajo consigo multitud de protestas en la Casa Blanca, al margen de un fuerte movimiento crítico. La cadena AMC aprovechó ese hecho para colocar, justo al lado, otra lona publicitaria gigante con una imagen igual (misma estampa, misma perspectiva) salvo que en vez de aparecer Obama, el protagonista de la imagen (que lleva la misma cazadora) es el protagonista de Breaking Bad. En el anuncio aparecía la leyenda "You got no proof. Getting away with it since 2008. A dealer in style" haciendo el símil con la leyenda que aparecía en la campaña de Wheaterproof ("Wheaterproof. A leader in style since 1948").

Imagen 3

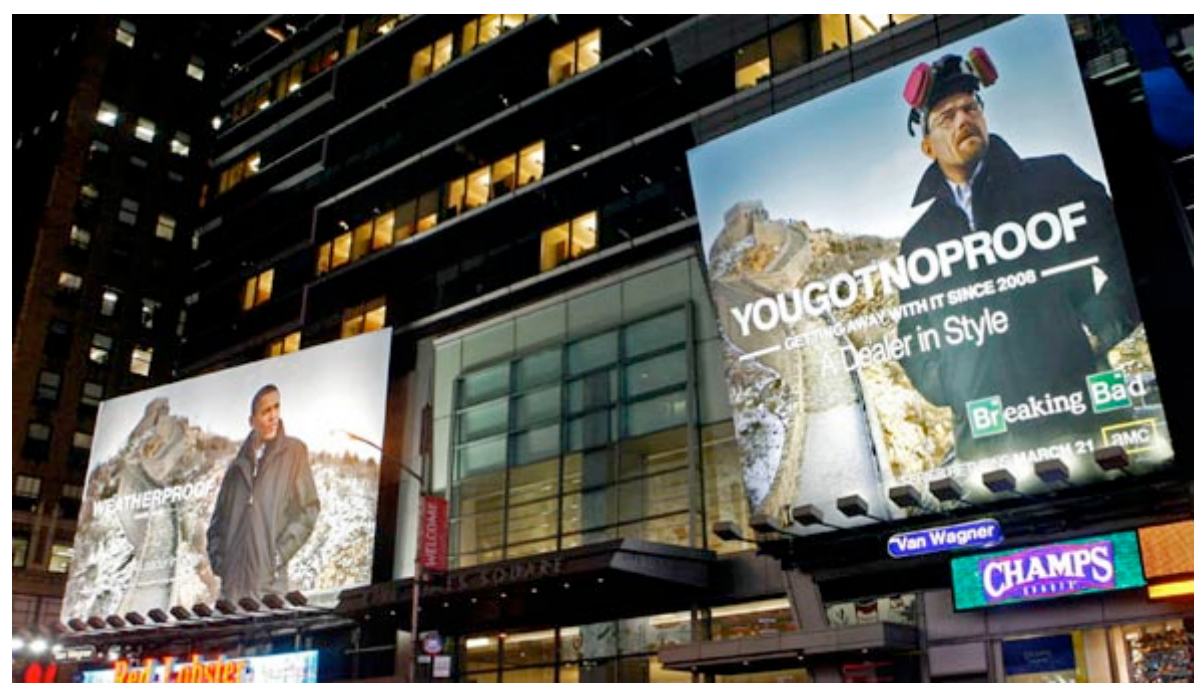

También nos gustaría comentar el caso de la publicidad a través de internet mediante marketing viral. Y es que, en Breaking Bad se da una integración de la diégesis (ficción) con el mundo real (no ficción) que ha dado una vuelta más para completar una campaña publicitaria que supera los límites de la propia serie: En un momento determinado, el hijo del protagonista decide crear una web para recaudar fondos para pagar el tratamiento de su padre. Esta web existe, es real (http://www.savewalterwhite.com ) y se ha ido transmitiendo entre usuarios (seguidores y no seguidores de la serie) que pueden (podemos) hacer 
donaciones reales que van a parar a la National Cancer Coalition (asociación nacional estadounidense contra el cáncer). A día de hoy, la web contempla un número de visitas de 26.669 personas.

Un caso similar, también transmitido vía viral, es el caso de la web de Saul, el abogado por excelencia de la serie, quien también tiene su web en el mundo real: http://www.bettercallsaul.com.

Además de todo esto, la estrategia publicitaria de la serie se extiende también a las aplicaciones para teléfonos del tipo smartphones. Para los dispositivos con sistema operativo Android, podemos encontrar multitud de aplicaciones con distintos usos: estar al día en cuanto a noticias sobre la serie, usar imágenes de la serie de fondos de pantalla, utilizar tonos de llamada con la sintonía principal o sonidos de distintos personajes de la serie (o alarmas)... incluso una campana de llamada (de las que se usan en las conserjerías de los hoteles) que explosiona. La aplicación quizá más sorprendente y dinámica, que también puede descargarse para los teléfonos Apple, es la "Breaking Bad: G.F.Y. (Go Fring Yourself ${ }^{4}$ )" con la que el usuario, compartiendo una fotografía, puede cambiar la cara del personaje Gus Fring por la suya propia (o la de otra persona) en la escena final de la temporada 4, viviendo en primera persona dicha escena y, por tanto, protagonizando la serie.

Esta última aplicación ofrece una experiencia muy impactante aunque similar a otra que se había ofrecido a los fans mediante la página web www.waltswarning.com. En ella, se podía disfrutar de un vídeo interactivo que introducía al usuario directamente en el mundo de Breaking Bad. Mediante una grabación de estilo subjetivo, el usuario se encontraba secuestrado por el personaje de Walter White muy enfadado y dirigiéndose en todo momento al usuario (a cámara), llamándole por su nombre y quemando una foto del mismo. Lógicamente, requería que estas informaciones personales fueran introducidas previamente, pero la sensación de protagonizar la escena estaba muy conseguida. Incluso permitía cambiar el punto de vista de la cámara (la visión del secuestrado, o sea, el usuario) mediante el movimiento del ratón de nuestro ordenador.

Y, a modo de anécdota, es importante destacar otras acciones curiosas, como la existencia de una enciclopedia virtual sobre la serie. Podemos encontrarla en e: http://breakingbad.wikia.com/wiki/Breaking_Bad_Wiki.

\section{En España: Primero Paramount Comedy, luego los canales autonómicos}

España no es un país que, por el momento, pueda presumir de creatividad o planificación estratégica ejemplar a la hora de promocionar el audiovisual, nos refiramos a cine, nos refiramos a series. Países como Francia o Estados Unidos, por poner ciertos ejemplos, parten con una previsión presupuestaria inicial que contempla el plan de publicidad, considerando la

\footnotetext{
${ }^{4}$ «Conviértete en Fring»
} 
promoción como una herramienta tan necesaria como la propia producción. Así, en ocasiones, ocurre que lo invertido en la producción de una serie es incluso inferior a la promoción de la misma. Casos míticos, como la promoción de la serie de J. J. Abrams, Perdidos $^{5}$ (Lost, ABC, 2004-2010), no hacen más que ejemplificar este hecho.

No obstante, y a pesar de que las acciones promocionales y publicitarias para la series en España vienen siendo modestas, también es cierto que hemos encontrado acciones publicitarias curiosas en relación a la serie que nos ocupa.

A modo de explicación hemos de reseñar que la serie Breaking Bad se estrenó en España el 11 de marzo de 2009 en la cadena Paramount Comedy, que había desembarcado en nuestro país diez años antes para ofrecer sus servicios de canal temático especializado en comedia mediante emisiones de televisión por cable o por satélite bajo fórmulas de pago.

De manera paralela, y de forma independiente, la FORTA (Federación de Organismos de Radio y Televisión Autonómicos) anunció la compra de sus derechos de emisión en mayo de 2009 (Forta, 2010), aunque no ofrecerían el estreno de la serie hasta tiempo después. Concretamente, las primeras en estrenarla fueron las televisiones autonómicas de Canarias y Aragón (TVCanaria en 2010 y Aragón TV en enero de 2011), marcando un patrón de programación de madrugada que después seguirían casi todas sus socias en la federación. Respectivamente, comenzaron a emitirla a las 01:55 y las 01:30 horas, dificultando en gran medida el seguimiento y fidelidad a la serie por parte de los telespectadores. Este es un aspecto que resulta importante a la hora de analizar la promoción publicitaria partiendo de que el éxito de la audiencia se ha visto muy condicionada por la pésima franja horaria de emisión. Así, aunque los medios utilizados para dar a conocer y promover la serie han sido correctos, cierto es también que, como se reseñaba unas páginas atrás, la distribución en España no ha sido (ni está siendo) la mejor.

La televisión catalana le otorgó mayor confianza y la estrenó a través de su canal multiplataforma 3XL en horario de prime time el 28 de abril de 2011 . Poco después, el 29 de mayo de ese mismo año, lo haría el ente autonómico madrileño a través de su segundo canal, LaOtra.

Ese mismo verano, varias de las restantes cadenas autonómicas pertenecientes a la FORTA siguieron los pasos de sus predecesoras. ETB, en el País Vasco, la programó en sus canales ETB-2 y ETB-3 con distintos horarios nocturnos a partir del 3 de julio. Días después, concretamente el 9 de julio, Canal Sur TV comenzó su emisión en su primer canal, como también hizo la televisión gallega TVG. El mes siguiente, en agosto de 2011, se les unió IB3 en las Islas Baleares.

\footnotetext{
${ }^{5}$ En Estados Unidos, meses antes del estreno del primer capítulo de la primera temporada, a los pasajeros de una serie de vuelos en diversos aeropuertos norteamericanos se les hizo entrega de un kit de supervivencia (patrocinado por la productora) para usar en caso de accidente en una isla desierta. El presupuesto de esta acción rondó aproximadamente los 200.000 dólares (Lagoa, 2012).
} 
Así, y ante este panorama de emisiones, haciendo un recorrido por las campañas llevadas a cabo por los distintos canales que han emitido la serie en España encontramos:

\subsection{Paramount:}

Como se viene comentando, ha sido el canal que ha prestado más atención a la emisión de la serie y a su promoción. Destacamos algunas de las autopromociones realizadas:

"Los diez mandamientos": Realizando una contraposición, es una autopromoción que busca enfrentar la locución de los diez mandamientos del Antiguo Testamento con la ruptura de estos preceptos por parte de los protagonistas de la serie. Para ello une, mediante el montaje, cada uno de los mandatos divinos con partes de escenas donde se observa justo el comportamiento contrario a lo que escuchamos, consiguiendo sorprender al espectador mediante este contraste de ideas. Sigue, de esta manera, la línea de algunos de los términos con los que la crítica define la serie: arriesgada, subversiva, que cuestiona los principios morales, ilegal... buscando el apoyo de la crítica. También aparecen otras referencias religiosas, como un primer plano de una mano ensangrentada, herida en la palma como las representaciones del Cristo crucificado; o un giro final ("Amarás a tu dios, el dinero, sobre todas las cosas") que explica la lectura irónica del discurso anterior, lo que consigue provocar una reflexión en el espectador tras la visualización de la autopromoción (necesaria para entenderla $)^{6}$.

"Azúcar": Se da un nuevo juego de contraste entre la inocencia de la canción infantil y algunas imágenes que pueden resultar cómicas o positivas, y el dramatismo y peligrosidad del resto de imágenes y situaciones que muestra sobre el tráfico y el consumo de drogas. La canción que aparece de manera protagonista es "A spoonful of sugar", cantada por Julie Andrews en la película Mary Poppins (P.L. Travers, 1964). Es una metáfora sobre cómo buscar el divertimento o el placer en el trabajo o las tareas que no nos son agradables en un principio, gracias a un elemento atractivo ("con un poco de azúcar esa píldora que os dan, pasará mejor" dice la versión en español) o a un cambio del punto de vista de la situación. El tema musical original acompaña una escena en la que Mary Poppins intenta que algo en principio negativo para los niños, ordenar el cuarto, se convierta en algo positivo y divertido. En este caso, la píldora a la que se refiere la letra ("the medicine", en su versión original en inglés) puede entenderse como guiño a las drogas, así como ese cambio de punto de vista puede hacer referencia a la valoración moral de la actitud del protagonista de la serie, que actúa, al menos al principio de la trama, movido por el bien de su familia, lo que puede transformar los sentimientos negativos hacia sus delitos en comprensión e identificación?

\footnotetext{
${ }^{6}$ http://www.paramountcomedy.es/programas/breakingbad/episodios/breaking-bad-promo-diezmandamientos (consultado el 14/01/2013).

7 http://www.paramountcomedy.es/programas/breakingbad/episodios/breaking-bad-promoazucar/video/ breaking-bad-529332/ (consultado el 12/01/2013).
} 
Genérica 1: Es un spot en el que se relacionan una serie de ideas entre la droga (uno de los temas principales de la serie) y la serie en sí. Se da un juego de confusión de cualidades entre ambas al mezclar escenas donde se habla de la droga, con críticas que califican a la serie de "droga dura", "adictiva" o "ilegal". Los diálogos pueden entenderse como referentes a la droga o a la serie:

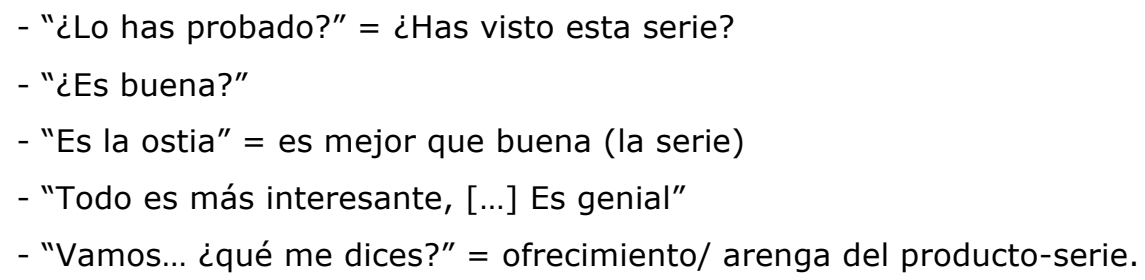

El mensaje final (sólo texto): "¿Te atreves?" es una interlocución al espectador donde se juega con la idea de la peligrosidad de la droga y del premio, el efecto de su consumo: el placer que no está al alcance de quien no se arriesga a probar algo fuera de los cánones establecidos.

A esto añadimos que la música que acompaña a la autopromoción es "Where is my mind", del norteamericano (Boston) grupo Pixies. La letra confusa y onírica junto con el sonido de guitarras agudas ayudan a crear una sensación de peligrosidad y placer turbio que sugiere el mundo de las drogas.

Esta autopromoción podemos verla en: http://www.paramountcomedy.es/programas/breakingbad/episodios/breaking-badengancha/video/ breaking-bad-527581/

Genérica 2: Presentada por Bryan Cranston, actor protagonista de la serie, la pieza presenta las dudas de su personaje sobre si seguir adelante en su proyecto de ganar dinero fabricando y vendiendo droga, presentando a su vez un ofrecimiento que él recibe para ganar 3 millones de dólares a cambio de trabajar para alguien que parece ser policía o algún cargo público respetable. Nuevamente aparece la cuestión moral de su protagonista y, por extensión/identificación, del espectador, ya que se entiende que la trama le ofrece la posibilidad de cambiar de bando y seguir ganando dinero (para su familia, recordemos) pero dejando de delinquir. La autopromoción la cierra el propio Cranston señalando el canal de emisión, Paramount Comedy.

Podemos ver esta autopromoción en http://www.paramountcomedy.es/programas/breakingbad/episodios/breaking-bad-episodio26/video/ breaking-bad-521888/.

\subsection{Canal Sur TV:}


Encontramos que este canal autonómico, Canal Sur TV, ofrece para la promoción de la serie, la propia web corporativa de RTVA donde se describe, mediante textos, tanto la sinopsis de la serie como los personajes principales o el argumento de los distintos capítulos divididos por temporadas ( $1^{a}$ y $\left.2^{a}\right)$, acompañados por algunas fotos.

Sin embargo, la promoción videográfica que descubrimos es muy escasa y poco descriptiva. En la única pieza que puede encontrarse en la página web dedicada a la serie, observamos la presentación de la historia de un hombre que parece que oculta su nueva ocupación a su mujer, que se dedica a algún negocio ilícito y que es capaz de matar con sus propias manos. Nos resulta un planteamiento muy plano en comparación con las autopromociones creadas por Paramount Comedy, mucho más ricas en matices, que presentan la trama de la serie envuelta en conflictos morales y mostrando mayor riqueza tanto visual como de contenido. En ésta de Canal Sur, sólo apreciamos que su protagonista mata por dinero y engaña a su esposa, pero no aparece nada acerca del motivo que le puede llevar a ese comportamiento. $\mathrm{Ni}$ siquiera existe alguna referencia al mundo de las drogas, fundamental en la trama. Tan sólo mediante la ambientación de las casas, típicas de la clase media estadounidense, observamos cierta contradicción entre el comportamiento que esperamos de personas que viven en ese ambiente y el proceder del personaje que interpreta Bryan Cranston.

\section{3. $E T B-2(E T B)$}

La televisión vasca sí le ha dado algo más de protagonismo a la serie. Para su difusión realizó una autopromoción de 30 segundos con motivo de su estreno, una pieza en la que destaca la ausencia de imágenes violentas, sobre todo en comparación con las autopromociones de la mayoría de los demás canales que emiten la serie. Ambienta la trama en el mundo de las drogas con la presentación de los agentes antidroga (DEA) y del protagonista, Walter White, y su socio, pero no utiliza ni el montaje rápido, ni imágenes espectaculares, ni siquiera alguna escena de los bajos fondos por donde suele discurrir la historia. Se trata, por tanto, de una autopromoción que podría denominarse "blanca" o "políticamente correcta", que no llama la atención ni describe la acción de la serie. En vez de ello, sugiere la existencia del conflicto entre los productores/traficantes de droga y los agentes que lo persiguen, pero no aporta mucho más en relación a los numerosos elementos de Breaking Bad. En este sentido, se asemejaría a la autopromoción emitida por Canal Sur TV, al resultar plana y poco elaborada, tanto visualmente como en su contenido discursivo.

Podemos ver esta autopromoción en: http://www.eitb.com/es/videos/detalle/916022/videopromocion--breaking-bad-partir-3-julio-etb2/ 


\subsection{LaOtra (Telemadrid)}

Telemadrid realizó una serie de cuatro autopromociones de 25 segundos para anunciar el estreno de la serie en su canal LaOtra. En ellas observamos una estructura común y algunas variaciones sobre dicha estructura. Comienzan presentando al personaje de Walter White en clase, junto a la pizarra, acompañado de la locución "hoy, en clase de química..." mientras se muestran elementos de la tabla periódica. Tras ello, en cada una de las piezas se menciona un elemento diferente, y se hace referencia a alguna de sus cualidades siempre relacionada con el mal: plomo-municiones, plata-riqueza, fósforo-llama (fuego) y azufre-infierno. Las imágenes de disparos, explosiones y otras situaciones ilícitas y de riesgo dan a entender al espectador la acción y peligrosidad del ambiente en que se mueve la trama, y consiguen provocar la sorpresa al relacionar un comienzo tan aparentemente normal y tranquilo en el ambiente escolar, con las posteriores acciones violentas. Tras nombrar la serie, se observan pequeños fragmentos de diálogos en los que se nos vuelve a presentar el personaje de Walter, bien presentándose mientras él mismo se graba ("Me llamo Walter White"), provocando la confusión y la curiosidad del espectador ("Esto no es una confesión de culpabilidad" o "Nada es cierto de lo que parece"), o bien con otro personaje dudando de su cambio ("¿Un hombre honrado como usted, va de pronto y se vuelve malo?").

El mensaje final en todas las autopromociones es "tus padres prefieren que hagas pellas" (no asistir a la clase), remarcando el carácter irreverente, peligroso y "de mal ejemplo" de la serie y buscando transmitir el sentido transgresor (con la ley) que suele atraer al público juvenil.

Podemos ver esta autopromoción en:

http://www.telemadrid.es/?q=corporativo/notasprensa/laotra-estrena-breaking-bad-lalucha-de-un-hombre-que-recurre-al-delito-para

\section{5. $3 X L(T V 3)$}

El canal 3XL ha sido uno de los pocos canales autonómicos en España que han cuidado la promoción de la serie (un ejemplo lo tenemos en http://www.tv3.cat/ptv3/tv3Searching.jsp?textBusca=breaking+bad). Este canal multiplataforma inició sus emisiones el 19 de septiembre de 2010 y las cesó el 1 de octubre de 2012, dentro de la reducción de costes que hizo la radiotelevisión pública catalana. La serie pasó entonces a emitirse en el canal principal de la corporación, TV3.

Además de su web oficial con información (y seguimiento) de la serie, con galería de fotos y descripción de los personales, la web de 3XL ofrecía capítulos a la carta, enlace con un blog propio sobre la serie, así como otra serie de elementos promocionales: 
Autopromoción genérica de 32": "No et perdis "Breaking Bad"^n. Receta: Walter y su socio cocinando la droga en una furgoneta. Se acompaña de música electrónica.

Autopromoción para el estreno de Breaking Bad + The In betweneers $\left(37^{\prime \prime}=25+12\right)$ : Presentación de la trama principal y del conflicto de arranque de la serie: la enfermedad de Walter y su decisión de producir droga para obtener dinero para su familia.

Moments Breaking Bad: Selección de momentos de la serie, fundamentalmente del personaje de Walter.

Personatges immorals: Análisis de los protagonistas de muchas de las series actuales y del nuevo modelo antisocial y de comportamiento reprobable al que pertenecen. Incluye referencias a Breaking Bad, remarcando de ella su sordidez, su humor negro y la contradicción en la que se mueve su protagonista como factores de su éxito.

\subsection{Otras autonómicas}

Otras televisiones autonómicas como IB3 (televisión de las Islas Baleares), redujeron la promoción de la serie a su web (http://ib3tv.com/20120717_184686-breaking-bad.html).

Aragón TV, se limitó a la web con sinopsis de la serie y tres minúsculas fotos (http://www.aragontelevision.es/index.php/mod.noticias/mem.detalle/idnoticia.42900/relcat egoria.1107/idmenu.94/chk.87ce97950d3ebcb9ddf37349014c84f0.html).

O TV Asturias, que también acudió única y exclusivamente a la información de su web (http://www.rtpa.es/tpa-parrilla:Breaking\%20Bad_48849.html) siendo especialmente curiosa la información que aparece de la serie "serie apta para todos los públicos"; al igual que la televisión gallega, TVG, quien sólo recoge someramente la serie a través de su página en la red: http://www.crtvg.es/crtvg/crtvgviva/tvg-estrea-esta-noite-a-serie-breaking-badun-drama-de-como-nos-pode-cam-biar-a-vida-cando-xa-non-queda-nada-queperder\#.URQPkPLueSp.

\section{Conclusiones}

Desde una óptica del marketing, hemos de decir que la estrategia ideal de promoción de un producto (también audiovisual) es tener la mejor mezcla de las variables del marketing mix en su óptima proporción. Cuando más, si nos situamos en el lado de la publicidad.

Porque una gran campaña publicitaria, si bien es cierto que no es éxito seguro que garantice la compra (o visionado, alquiler, seguimiento, -descarga-) de una serie, sí que la labor de promoción ayuda a conseguir que los posibles espectadores, cuanto menos, se acerquen a ella. Obviamente, si el producto no consigue enganchar al espectador, poca labor podrá desempeñar la campaña publicitaria. Pero, insistimos, una campaña puede conseguir que, 
teniendo una buena serie, el número de espectadores que se aproximen a ella sea muy superior al que tendría la serie sin campaña, sin promoción.

En este capítulo hemos intentado demostrar la importancia que ha adquirido la promoción de contenidos para las cadenas de televisión y para las propias productoras. Y, sin embargo, nos ha sorprendido especialmente que Breaking Bad ha tenido una promoción muy inferior a las campañas protagonizadas por series de la competencia (Juego de Tronos) o incluso de la misma factoría (Mad Men). Pero la sorpresa es aún mayor cuando observamos que, en el caso de España, no sólo la promoción ha sido limitada, sino que incluso las emisiones por parte de los canales autonómicos (FORTA) han relegado la serie a franjas horarias imposibles... Evidentemente sus campañas publicitarias, en los casos en los que las ha habido, tampoco han supuesto un modelo publicitario a desarrollar, dado que éstas han sido, cuanto menos, pobres, escasas y faltas de creatividad.

Por todo ello nos cuesitonamos: ¿Hasta qué punto el éxito de crítica de otros países ha sido la causante del éxito en España? ¿Ha servido la escasa promoción de Breaking Bad en España para conseguir algún objetivo de marketing? Quizás nos sirva esta reflexión para tener un nuevo punto de partida en la promoción de las series.

\section{REFERENCIAS BIBLIOGRÁFICAS}

GARCíA UCEDA, Mariola (1997): Las claves de la publicidad. 2a Edición Revisada, Madrid, ESIC.

AAKER, D. (2005): Liderazgo de marca, Barcelona, Deusto.

Álvarez Monzoncillo, J.M. (1994): "El sector audiovisual en España y Europa. Perspectivas de la industria audiovisual española: un difícil reto en el marco europeo", en Telos, 39: septiembre-noviembre, pp. 101-110.

Amiguet, J.M. (2000): "El factor distribución en el marketing del cine: razones para su relevancia estratégica", en Caleidoscopio, revista del audiovisual, 1, pp. 1-13. Valencia, Universidad Cardenal Herrera, - CEU.

BALMASEDA, E. (1994): "El sector audiovisual en España y Europa. Por una industria de dimensión europea: diagnosis y propuestas", en Telos, 39: septiembrenoviembre, pp. 73-78.

Costas, N. y VALderRamA, M. (2012): "Las series como elemento de diferenciación y autopublicidad televisiva. Análisis comparativo de las promociones de "flashforward": Estados Unidos (ABC) vs. España (cuatro)", en Ámbitos, 21, pp. 119-143.

díez de Castro, E.C., Martín Armario, E. y Sánchez Franco, M. J. (2002): Comunicaciones de marketing, Madrid, Pirámide.

FERnÁNDEZ, J.D. y LABARTA, F. (2005): Cómo crear una marca. Manual de uso y gestión, Córdoba, Almuzara. 
GonzÁlez OÑATE, C. (2006): La continuidad televisiva en la era digital. Nuevos discursos publicitarios de expresión de Identidad Corporativa. El nacimiento de Cuatro. Tesis Doctoral, Universidad Jaume I.

JimÉnEZ, G. Y ELÍAS, R. (2013): "Caza y captura del espectador: Publicidad y promoción de la serie Juego de Tronos en Estados Unidos y España en medios convencionales" en Lozano, J., Raya, I. y López, F. (2013): Reyes, espadas, cuervos y dragones. Estudio del fenómeno televisivo Juego de Tronos, Madrid, Fragua, 2013.

JohnSton, K. N. (2009): Coming Soon. Film Trailers and the Selling of Hollywood Technology, North Carolina, McFarlandbooks.

Keller, K. (2008): Administración estratégica de marca, México, Pearson.

KERRIGAN, F. (2009): Film marketing, Oxford: Butterworth-Heinemann.

KOTLER, P. (2010): Marketing 3.0. Madrid, Lid.

LAGOA, M. (2012): "Series en promoción: las diferencias entre $A M C$ y $H B O$ ", en EI País de 5 de marzo de 2012. Disponible en http://blogs.elpais.com/quintatemporada/2012/03/series-en-promocion-las-diferencias-entre-amc-yhbo.html (consultado el 20/12/2012).

LozANo, J. y HeRmidA, A. (2010): "La metamorfosis publicitaria digital. Nuevas estrategias de promoción en la industria del cine y la televisión a través de internet", en Actas del II Congreso Internacional AE-IC Málaga 2010: Comunicación y desarrollo en la era digital, Málaga, 2010. Disponible en http://www.ae-ic.org/malaga2010/upload/ok/254.pdf (consultado: 16/01/2013).

LozANO, J., RAYA, I. y LóPEZ, F. (2013): Reyes, espadas, cuervos y dragones. Estudio del fenómeno televisivo Juego de Tronos, Madrid, Fragua.

Prado, J.C. (1997): "Un marketing de película", en IPMark, No 4, pp. 1-31.

Ramos, M., Lozano, J. y Hernández-Santaolalla, V. (2012): "Fanadvertising y series de televisión", en Comunicación, 10: 1, pp. 1211-1223, 2012. Disponible en http://www.revistacomunicacion.org/pdf/n10/mesa7/094.Fanadvertising_y_ series_de_television.pdf (consultado el 23 de diciembre de 2012).

RocA ChILlidA, J.M. (1995): "Sector audiovisual y el proceso de los multimedia", Economía Industrial, 303: III, pp. 147-15.

SEMPRINI, A. (1995): El marketing de la marca. Una aproximación semiótica. Barcelona, Paidós.

[Recibido: 3 de junio de 2013. Aceptado: 16 de octubre de 2014] 